\title{
LETTER
}

\section{Duration of antibiotic therapy in bacteraemia}

\author{
Matt P Wise ${ }^{1 *}$, Matt PG Morgan² and Anton G Saayman' \\ See related research by Havey et al., http://ccforum.com/content/15/6/R267
}

Reducing duration of antibiotic therapy without a diminution in efficacy decreases cost, side effects, antibiotic related diarrhoea, and bacterial resistance. Havey and colleagues [1] reported the results of a systematic review and meta-analysis of antibiotic duration in bacteraemia and deduced short course therapy ( $<7$ days) might be as effective as longer treatments. It is surprising given the obvious benefits and the frequency with which bacteraemia is documented in critically ill patients that there is such a paucity of randomised clinical trials (RCTs) comparing duration of therapy. Only one RCT, in neonates, had been performed in patients solely with bacteraemia. Accordingly, Havey and colleagues concluded that duration of antibiotic therapy in bacteraemia is poorly studied and would benefit from a large RCT.

Daneman and colleagues [2] performed a survey of Canadian infectious disease and critical care specialists to gauge the optimal duration of therapy in bacteraemic critically ill patients. Considerable variability existed amongst clinicians and undoubtedly reflects the lack of robust data to guide best practice. However, length of treatment is only one aspect of optimising outcomes from antibiotic use. Future RCTs need to take into account whether adequate source control has been achieved, as this will bias duration of therapy. Moreover, it is clear that since many antibiotics deployed in critical care demonstrate time-dependent killing, inadequate doses are frequently used, which increases treatment failure and the emergence of resistance $[3,4]$. Pharmacokinetic optimisation that ensures adequate time above minimum inhibitory concentration should therefore be an integral component of any trial that compares duration of antibiotic therapy [5].

\section{Abbreviations \\ $\mathrm{RCT}$, randomised clinical trial.}

\section{Competing interests}

The authors declare that they have no competing interests.

\section{Author details}

${ }^{1}$ Adult Critical Care, University Hospital of Wales, Cardiff, CF14 4XW, UK. 2Department of Anaesthesia, University Hospital of Wales, Cardiff, CF14 4XW, UK.

Published: 9 January 2012

\section{References}

1. Havey TC, Fowler R, Daneman N: Duration of antibiotic therapy for bacteremia: a systematic review and meta-analysis. Crit Care 2011, 15:R267.

2. Daneman N, Shore K, Pinto R, Fowler R: Antibiotic treatment duration for bloodstream infections in critically ill patients: a national survey of Canadian infectious diseases and critical care specialists. Int J Antimicrob Agents 2011, 38:480-485.

3. Taccone FS, Laterre PF, Dugernier T, Spapen H, Delattre I, Wittebole X, De Backer D, Layeux B, Wallemacq P, Vincent JL, Jacobs F: Insufficient $\beta$-lactam concentrations in the early phase of severe sepsis and septic shock. Crit Care 2010, 14:R126.

4. Seyler L, Cotton F, Taccone FS, De Backer D, Macours P, Vincent JL, Jacobs F: Recommended $\beta$-lactam regimens are inadequate in septic patients treated with continuous renal replacement therapy. Crit Care 2011, 15:R137

5. Roberts JA: Using PK/PD to optimize antibiotic dosing for critically ill patients. Curr Pharm Biotechnol 2011 [Epub ahead of print].

doi:10.1186/cc10590

Cite this article as: Wise MP, et al:: Duration of antibiotic therapy in bacteraemia. Critical Care 2012, 16:403.

*Correspondence: mattwise@doctors.org.uk

'Adult Critical Care, University Hospital of Wales, Cardiff, CF14 4XW, UK

Full list of author information is available at the end of the article 